\title{
Prognostic value of visual residual tumour cells (VRTC) for patients with esophageal squamous cell carcinomas after neoadjuvant therapy followed by surgery
}

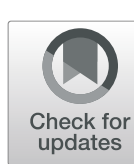

Xingxing Wang ${ }^{1 \dagger}$, Hao Wang ${ }^{2 \dagger}$, Haixing Wang ${ }^{1}$, Jie Huang ${ }^{1}$, Xin Wang ${ }^{1}$, Zhengzeng Jiang ${ }^{1}$, Lijie Tan², $^{2}$ Dongxian Jiang ${ }^{1 *}$ and Yingyong $\mathrm{Hou}^{1,3,4^{*}}$

\begin{abstract}
Background: We assessed visual residual tumour cells (VRTC) with both Becker's tumour regression grading (TRG) system and Japanese TRG system in esophageal squamous cell carcinoma (ESCC) patients treated with neoadjuvant therapy followed by surgery.

Methods: We compared Becker system and Japanese system in 175 ESCC patients treated between 2009 and 2015. Results: According to Becker system, the 5-year DFS/DSS rates were 70.0\%/89.3, 53.8\%/56.7, 43.0\%/49.0, and 42.4\%/ $39.1 \%$ for TRG 1a (VRTC 0), TRG 1b (1-10\%), TRG 2 (11-50\%), and TRG 3 (> 50\%). According to Japanese system, the rates were 38.8\%/34.1, 49.5\%/58.7, 50.2\%/49.0 and 70.0\%/89.3\% for Grade 0-1a (VRTC> 66.6\%), Grade 1b (33.366.6\%), Grade 2 (1-33.3\%) and Grade 3 (0). TRG according to two systems significantly discriminate the patients' prognosis. TRG according to Becker system (HR 2.662, 95\% Cl 1.151-6.157), and lymph node metastasis (HR 2.567, $95 \% \mathrm{Cl} 1.442-4.570$ ) were independent parameters of DSS.

Conclusions: Both Becker and Japanese system had their advantage in risk stratification of these ESCC patients. It was speculated that dividing 1-10\% VRTC into a group might contribute to independently prognostic significance of Becker's TRG system. Therefore, in addition to TRG of different systems, the percentage of VRTC might be recommended in the pathologic report, which could make the results more comparable among different researches, and more understandable for oncologists in the clinical practice.
\end{abstract}

Keywords: Neoadjuvant therapy, Esophageal squamous cell carcinoma (ESCC), Visual residual tumour cells (VRTC), Tumour regression grading (TRG), Lymph node metastases (LNM)

\footnotetext{
*Correspondence: jiangdongxian3@aliyun.com; houyingyong@aliyun.com

${ }^{+}$Xingxing Wang and Hao Wang contributed equally to this work.

'Department of Pathology, Zhongshan Hospital, Fudan University, Shanghai 200032, People's Republic of China

Full list of author information is available at the end of the article
}

(C) The Author(s). 2021 Open Access This article is licensed under a Creative Commons Attribution 4.0 International License, which permits use, sharing, adaptation, distribution and reproduction in any medium or format, as long as you give appropriate credit to the original author(s) and the source, provide a link to the Creative Commons licence, and indicate if changes were made. The images or other third party material in this article are included in the article's Creative Commons licence, unless indicated otherwise in a credit line to the material. If material is not included in the article's Creative Commons licence and your intended use is not permitted by statutory regulation or exceeds the permitted use, you will need to obtain permission directly from the copyright holder. To view a copy of this licence, visit http://creativecommons.org/licenses/by/4.0/ The Creative Commons Public Domain Dedication waiver (http://creativecommons.org/publicdomain/zero/1.0/) applies to the data made available in this article, unless otherwise stated in a credit line to the data. 


\section{Background}

Esophageal cancer (EC) is the ninth most common cancer and the sixth most common cause of cancer death globally [1]. Chinese population-based studies have shown approximately 477,900 persons receive a diagnosis of EC, and 375,000 persons died of EC in 2015, ranking it as the third most commonly diagnosed cancer and the fourth leading causes of cancer death in China [2]. Surgical resection has been the mainstay of treatment for EC. However, the majority of patients with locally advanced EC who undergo surgical resection eventually develop local recurrence or distant metastasis, and the 5 -year survival rate is only $5-34 \%$ [3]. In an attempt to improve survival, many investigators around the world have assessed multidisciplinary strategies. The preoperative neoadjuvant chemotherapy (nCT) or chemoradiotherapy (nCRT) combined with surgery have gained more attention in the treatment of locally advanced EC $[4,5]$. Several studies have shown that neoadjuvant therapy (nCT or nCRT) followed by surgery significantly improves disease free survival (DFS) and overall survival (OS) compared with surgery alone, making it standard therapy for locally advanced EC [6-9]. Accumulating evidence indicates that the histological evaluation of the regression response to $\mathrm{nCT}$ or $\mathrm{nCRT}$ is the most important predictor of survival $[5,10]$.

Tumour regression grade (TRG) system referring to the amount of therapy-induced fibrosis in relation to residual tumour after nCRT has been initially developed by Mandard and coworkers [11]. However, the reproducibility and prognostic value of this system has been challenged because of the difficulties in the assessment of the relative amount of fibrosis [12]. Then the quantitative analysis of regression response through the estimated percentage of visual residual tumour cell (VRTC) in relation to the previous tumour site has been proposed. At present, there are several classification systems ( 2 to 5 grades) available in the literature, with the cut-off value of 1,10 and 50\% [13-18]. Among the systems, a modification of 4-tiered Becker system not only resulted in statistically superior rates for interobserver agreement but also in achievement of a better prognostic impact in many reports [19]. Besides, TRG system with cutoff value of $1 / 3$ and $2 / 3$, according to Japanese Classification of Esophageal Cancer, has also been widely used in esophageal squamous cell carcinoma (ESCC) [20, 21]. The larger retrospective studies found that the Japanese system was also simple, reproducible and prognosisassociated [22, 23]. At present, there was no study to compare the application of the 2 major approaches (Becker system and Japanese system) for assessment of VRTC in ESCC after neoadjuvant therapy.

In the ESCC patients with neoadjuvant therapy, we compared the Becker system and Japanese system for assessment of VRTC, and tried to explore the prognostic factors.

\section{Methods \\ Patients}

This study was based on a retrospective review of 175 patients who underwent surgical resection following 2 to 3 cycles of neoadjuvant chemotherapy ( $\mathrm{nCT}$ ) or neoadjuvant chemoradiotherapy (nCRT) for ESCC, between November 2009 and December 2015 at Zhongshan Hospital, Fudan University, Shanghai, China. They were diagnosed as locally advanced-stage disease (clinical T34), using endoscopy, computed tomography (CT) of the chest and abdomen, endoscopic ultrasound, and positron emission tomography (PET), and required neoadjuvant treatment as first-line treatment prior to surgical resection. Informed consents were obtained from all patients. This study was approved by the Institutional Review Board of our hospital (B2016-135) and was performed according to the ethical principles of the Declaration of Helsinki.

The patients were followed up routinely in outpatients, every 3 months in the first year and every 6 months in the second year, followed by annual evaluations. Patients who did not go to our hospital were contacted by telephone to obtain follow-up data.

\section{Pathological analysis}

For specimens with neoadjuvant therapy in our hospital, all the suspected area of tumors were embedded and sectioned after the macroscopic examination, and all slides were evaluated by pathologists at once. For this study, all 175 surgically resected ESCC specimens were systematically reevaluated histopathologically by two experienced gastrointestinal pathologists. The histopathological review was undertaken with the pathologists blinded to the treatment results. The original tumour area was identified by signs of tumour regression changes, such as marked fibrosis, necrosis, flattening of the mucosa, or the presence of foreign body giant cell reaction. The extent of VRTC was assessed semiquantitatively, based on the estimated percentage of cancer in relation to the total cancer area [19-21]. With the repeated observation of tumour regression changes and training in evaluating standard, a consistency of $99 \%$ was achieved by the two pathologists. So far, several TRG systems have been used to assess the pathologic response to preoperative neoadjuvant therapy. In our study, the extent of VRTC was divided into four categories according to Becker regression criteria [19] or the Japanese Classification of Esophageal Cancer [20, 21].

Other clinicopathologic characteristics were also recorded, including age, gender, tumour location, tumour grade, tumour size (measured during the pathological 
sampling), lymphovascular invision, perineural growth, number of positive lymph nodes (LN), and the type of neoadjuvant.

\section{Statistical analysis}

Categorical data were analyzed using $\mathrm{x} 2$ test or Fisher's exact test. Survival curves were estimated using the Kaplan-Meier method and were compared using the log-rank test. Overall survival (OS) was defined as the period from the date of surgery until the last confirmed date of survival or the date of death. Disease specific survival (DSS) was defined as the period from the date of surgery until the date of death, because of ESCC. Disease free survival (DFS) was defined as the period from the date of surgery until the date of disease progression or the date of death, because of ESCC. The Cox proportional hazard model was used to examine the association between clinicopathological factors and survival, to identify independent prognostic factors. Hazard rates (HRs) with its $95 \%$ confidence intervals (95\% CIs) were used to determine the effect of each variable on outcome. Statistical analysis was performed using the SPSS software, version 21.0 (SPSS Inc., Chicago, IL), with statistical significance being considered with $P<0.05$ (two-sided).

\section{Results}

\section{Patient and general pathological characteristics}

The clinical and pathological characteristics of the 175 patients are summarized in Table 1.There were 148 male and 27 female patients with a mean age of 59.8 (range 41-73) years. Tumours were most often located in midesophagus $(n=82)$ compared with the upper third $(n=$ $29)$ or the lower third $(n=64)$. The mean tumour length was 2.9 (range $0.3-9.0) \mathrm{cm}$. One hundred eight patients $(61.7 \%)$ were treated with preoperative chemotherapy, whereas 67 (38.3\%) patients were treated with preoperative chemoradiotherapy. No residual tumour was found in 26 patients. Vessel and nerve invasion were identified in $57(32.6 \%)$ and $56(32.0 \%)$ tumours, respectively. In 83 patients who had positive LN status, 51 patients (61.5\%) had 1-2 positive LN, 23 patients (27.7\%) had 36 positive LNs, and 9 patients (10.8\%) had more than 6 positive LNs.

\section{Effect of neoadjuvant therapy on ESCC}

TRG system of Becker or Japanese Esophageal Cancer Association was widely accepted in western country or Japan, which was used in our study, separately. According to the Becker system, there were 26 cases (14.9\%) of TRG 1a, 36 cases $(20.6 \%)$ of TRG 1b, 33 cases $(18.9 \%)$ of TRG 2, and 80 cases (45.7\%) of TRG 3 (Fig. 1). Namely, 62 tumours $(35.4 \%)$ showed a histopathological response of TRG 1a or 1b, whereas the remainder showed minor or no response (Table 1). According to the Japanese system, there were 64 cases (36.6\%) of Grade 0-1a, 28 cases $(16.0 \%)$ of Grade 1b, 57 cases (32.6\%) of Grade 2, and 26 cases (14.9\%) of Grade 3. Namely, 83 tumours (47.4\%) showed a histopathological response of Grade 2 or 3, whereas the remainder showed minor or no response (Table 1).

Table 1 depicts the associations between TRG and different pathological variables. According to Becker and Japanese system, we found that more VRTC (reflecting poor response following neoadjuvant treatment) were significantly associated with longer tumour length, poorly differentiated tumour, lymphovascular invasion, perineural invasion, lymph node metastases (LNM) and single neoadjuvant treatment (Chemotherapy alone) $(P<$ 0.05) (Table 1).

\section{Survival analysis}

The median follow-up duration was 24.0 months (range, 2 to 86 months). At the time of analysis, 70 patients (40.0\%) had disease progression and 59 patients (33.7\%) had died of esophageal cancer. At total, 68 patients (38.9\%) died. The 1-, 2-, 3-, and 5-year postoperative DFS rates for the patients in this study were 82.8, 63.9, 57.6 , and 50.3\%, respectively. The 1-, 2-, 3-, and 5-year postoperative DSS rates for the patients in this study were 91.0, 73.4, 60.9, and 51.0\%, respectively. The 1-, 2-, $3-$, and 5 -year postoperative OS rates for the patients in this study were $88.8,72.4,56.9$, and $45.6 \%$, respectively.

\section{Histopathological TRG as a prognostic factor}

Histopathological TRG was found to be strongly associated with survival. When the patients were categorized according to Becker system (TRG 1a, TRG 1b, TRG 2, and TRG 3), the 5-year DFS rates were 70.0\% (median time 72 months), $53.8 \%$ (non-reached), $43.0 \% \quad$ (29 months), and $42.4 \%$ (32 months), 5-year DSS rates were 89.3\% (median time non-reached), 56.7\% (median time non-reached), $49.0 \%$ (34 months), and $39.1 \% \quad(36$ months), and the 5-year OS rates were $72.2 \%$ (median time 78 months), $50.0 \%$ (non-reached), $50.0 \%$ (34 months), and $34.1 \%$ (34 months), respectively. Significant differences in DFS and DSS were observed between patients with TRG $1 \mathrm{a} / 1 \mathrm{~b}$ and TRG2/3 $(P<0.05)$ but not between patients with TRG1a and TRG1b $(P>0.05)$ (Fig. 2). When the patients were categorized according to Japanese system (Grade 0-1a, Grade 1b, Grade 2 and Grade 3), the 5-year DFS rates were $38.8 \%$ (median time 32 months), $49.5 \%$ (36 months), $50.2 \%$ (non-reached) and $70.0 \%$ (72 months), the 5-year DSS rates were $34.1 \%$ (median time 36 months), 58.7\% (non-reached), 49.0\% (58 months) and $89.3 \%$ (non-reached), and the 5-year OS rates were $31.1 \%$ (median time 31 months), $52.8 \%$ (non-reached), $45.4 \%$ (58 months) and $72.2 \% \quad$ (78 months), respectively. Significant differences in DSS 
Table 1 Clinical and Histopathological Characteristics in 175 Patients With ESCC Treated With Neoadjuvant therapy Plus Surgical Resection

\begin{tabular}{|c|c|c|c|c|c|c|c|c|}
\hline & \multirow[t]{2}{*}{$\mathbf{n}$} & \multirow[t]{2}{*}{ Percent (\%) } & \multicolumn{3}{|c|}{ tumour regression grade (Becker) } & \multicolumn{3}{|c|}{ tumour regression grade (Japan) } \\
\hline & & & TRG 1a-1b & $\%$ & $P$ value & Grade $2-3$ & $\%$ & $P$ value \\
\hline$\overline{\text { Age }}$ & & & & & 0.168 & & & 0.231 \\
\hline$<60$ & 80 & 45.7 & 24 & 30.0 & & 34 & 42.5 & \\
\hline$\geq 60$ & 95 & 54.3 & 38 & 40.0 & & 49 & 51.6 & \\
\hline Gender & & & & & 0.530 & & & 0.935 \\
\hline Female & 27 & 15.4 & 11 & 40.7 & & 13 & 48.1 & \\
\hline Male & 148 & 84.6 & 51 & 34.5 & & 70 & 47.3 & \\
\hline Anatomic location & & & & & 0.118 & & & 0.221 \\
\hline Upper third & 29 & 16.6 & 15 & 51.7 & & 18 & 62.0 & \\
\hline Middle third & 82 & 46.9 & 25 & 30.5 & & 37 & 45.1 & \\
\hline Lower third & 64 & 36.6 & 22 & 34.4 & & 28 & 43.8 & \\
\hline Size & & & & & 0.004 & & & $<0.001$ \\
\hline$<3 \mathrm{~cm}$ & 90 & 51.4 & 41 & 45.6 & & 58 & 64.4 & \\
\hline$\geq 3 \mathrm{~cm}$ & 85 & 48.6 & 21 & 24.7 & & 25 & 29.4 & \\
\hline Lymphovascular invasion & & & & & $<0.001$ & & & $<0.001$ \\
\hline Negative & 118 & 67.4 & 59 & 50.0 & & 70 & 59.3 & \\
\hline Positive & 57 & 32.6 & 3 & 5.3 & & 13 & 22.8 & \\
\hline Perineural growth & & & & & $<0.001$ & & & $<0.001$ \\
\hline Negative & 119 & 68.0 & 58 & 48.7 & & 73 & 61.3 & \\
\hline Positive & 56 & 32.0 & 4 & 7.1 & & 10 & 17.9 & \\
\hline Lymph-node metastasis & & & & & $<0.001$ & & & $<0.001$ \\
\hline Negative & 92 & 52.6 & 46 & 50.0 & & 57 & 62.0 & \\
\hline Positive & 83 & 47.4 & 16 & 19.3 & & 26 & 31.3 & \\
\hline ypN-stage & & & & & $<0.001$ & & & $<0.001$ \\
\hline ypNo & 92 & 52.6 & 46 & 50.0 & & 57 & 62.0 & \\
\hline ypN1 & 51 & 29.1 & 12 & 30.8 & & 20 & 39.2 & \\
\hline ypN2 & 23 & 13.1 & 4 & 17.4 & & 6 & 26.1 & \\
\hline ypN3 & 9 & 5.1 & 0 & 0 & & 0 & 0 & \\
\hline Type of neoadjuvant & & & & & $<0.001$ & & & $<0.001$ \\
\hline Chemotherapy & 108 & 61.7 & 23 & 21.3 & & 30 & 27.8 & \\
\hline Chemoradiotherapy & 67 & 38.3 & 39 & 58.2 & & 53 & 79.1 & \\
\hline \multicolumn{9}{|c|}{ tumour regression grade (Becker) } \\
\hline TRG1a & 26 & 14.9 & & & & & & \\
\hline TRG 1b & 36 & 20.6 & & & & & & \\
\hline TRG2 & 33 & 18.9 & & & & & & \\
\hline TRG3 & 80 & 45.7 & & & & & & \\
\hline \multicolumn{9}{|c|}{ tumour regression grade (Japan) } \\
\hline G0-1a & 64 & 36.6 & & & & & & \\
\hline G1b & 28 & 16.0 & & & & & & \\
\hline G2 & 57 & 32.6 & & & & & & \\
\hline G3 & 26 & 14.9 & & & & & & \\
\hline
\end{tabular}




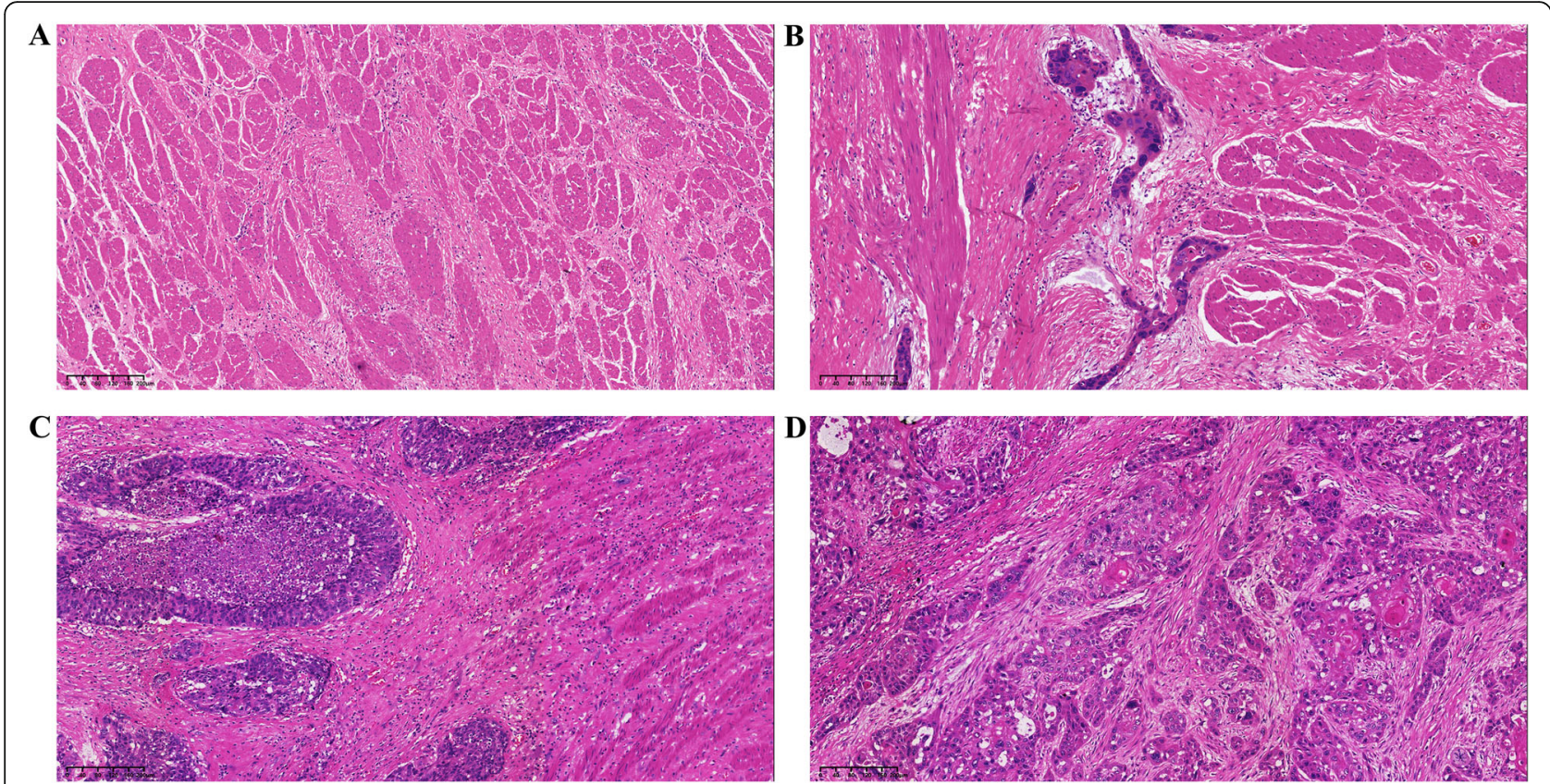

Fig. 1 Histologic examples of different extent of visual residual tumour cells (VRTC) in ESCC treated with neoadjuvant therapy and surgery (100x): a no VRTC: evident fibrosis and chronic inflammatory infiltrate without detectable tumor cells (TRG 1a according to Becker system or Grade 3 according to Japanese system); $\mathbf{b}$ little VRTC: fibrosis with rare small groups of tumor cells (TRG $1 \mathrm{~b}$ according to Becker system or Grade 2 according to Japanese system); c many VRTC: fibrosis and tumor cells with preponderance of tumor cells; and $\mathbf{d}$ no regression response: no signs of treatment effect

were observed between patients with Grade 3 and those with Grade 0-1a, 2 and $3(P<0.05)$ (Fig. 3).

\section{Independent prognostic factors}

The univariate analysis showed a significant DFS difference in 5 factors: tumour grade, lymphovascular invasion, perineural growth, LNM, and TRG. The univariate analysis showed a significant DSS difference in 6 factors: tumour size, lymphovascular invasion, perineural growth, LNM, and TRG. The multivariate analysis identified that TRG (Becker system) (HR, 2.050; 95\% CI, 1.084 to 3.878 for DFS) (HR, 2.367; 95\% CI, 1.123 to 4.991 for DSS) was potentially independent factor of DFS and DSS. Beside TRG, LNM (HR, 1.770; 95\% CI, 1.069 to 2.932 for DFS) (HR, 2.496; 95\% CI, 1.416 to 4.402 for DSS) was also independent factor of DFS and DSS (Table 2).

\section{Discussion}

In the present study, we retrospectively analyzed the clinicopathological data and outcomes of 175 patients with ESCC who underwent $\mathrm{nCT}$ or nCRT followed by surgery and elucidated the relationships between the clinicopathological characteristics. We designed the current investigation specifically focusing on patients with ESCC, which is the most common histological subtype of EC, particularly in China [2]. To the best of our knowledge, less related study has been conducted in China.

\section{Neoadjuvant therapy}

Prior to the emergence of chemotherapy and radiotherapy, surgical resection had been the curative treatment of first choice in EC. At present, neoadjuvant therapy is used widely for patients with locally advanced EC. Evidence indicates that neoadjuvant therapy ( $\mathrm{nCT}$ or nCRT) significantly improves survival in patients with locally advanced EC compared with surgery alone [4, 6 , $7]$. In our series, the 5 -year survival rate was $45.6 \%$. In our center, the 5 -year survival rate was $39.7 \%$ for patients undergoing surgery alone [24]. Other results [25] showed significant $13 \%$ increase in 5-year survival for neoadjuvant therapy plus surgery as compared with surgery alone.

A reliable prognostic factor for ESCC patients undergoing neoadjuvant therapy is lacking. As preoperative neoadjuvant therapy has been used increasingly in the management of locally ESCC patients, the identification of potential prognostic parameters in these patients has recently gained momentum.

\section{Histopathological evaluation of tumour response}

Histopathological tumour response after neoadjuvant therapy is believed to be an important objective factor 

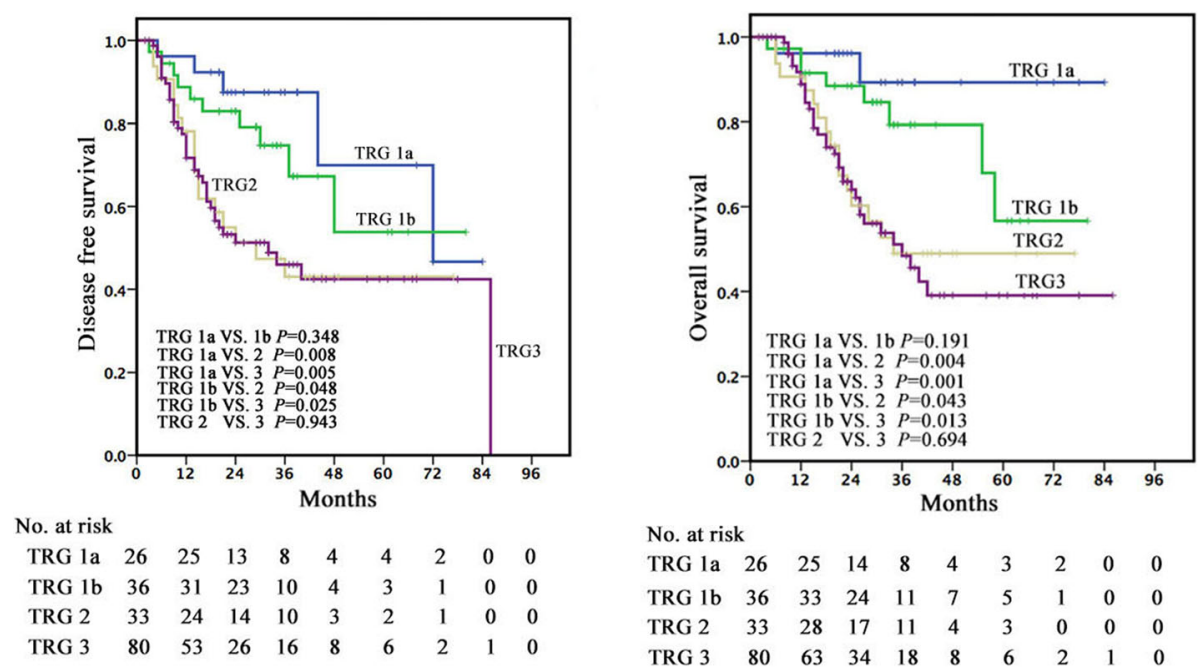

Fig. 2 Kaplan-Meier curves for DFS and DSS in patients with ESCC treated with neoadjuvant therapy and surgery stratified by tumour regression grade according to Becker system

and has been shown to have prognostic value in several studies [12-14, 26]. Response of the primary tumour can range from the absence of response to a total response with no VRTC. There is a consensus that the patients with pathologic complete response after neoadjuvant therapy benefit from these treatment modalities with 5-year survival rates up to $60 \%[25,27,28]$. Partial tumour response is a matter of ongoing debate with controversial results from different trials [23, 29].
There are several classification systems available in the literature, with classification of responders varying from a 1 to $50 \%$ of VRTC $[15,30]$. We present a brief review of the literature on classification systems used to assess the pathologic response to preoperative neoadjuvant therapy, and outline the most commonly used TRG systems, to assess if tumour regression does predict statistically significant improvement in OS and DFS.
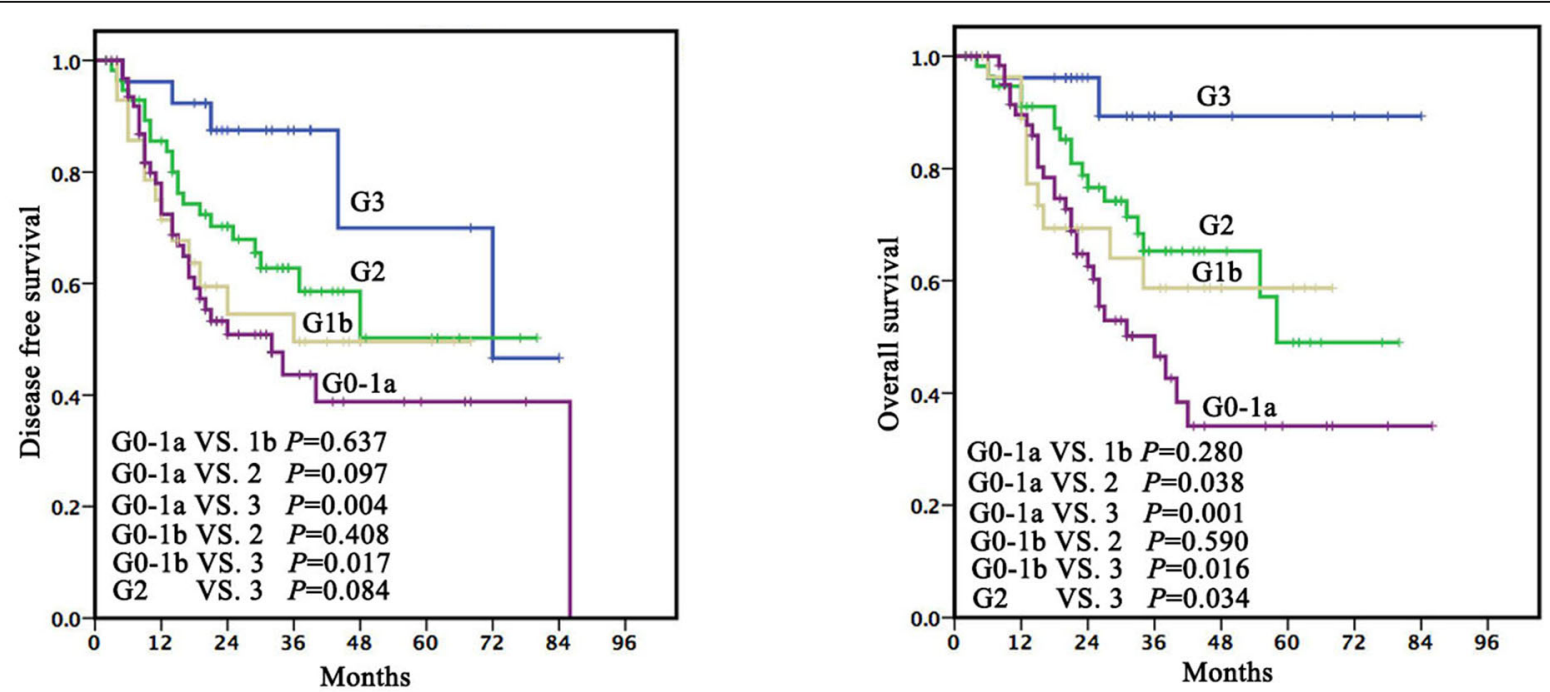

No. at risk

$\begin{array}{lccccccccc}\text { G0-1a } & 64 & 41 & 21 & 11 & 6 & 4 & 2 & 1 & 0 \\ \text { G1b } & 28 & 20 & 11 & 10 & 4 & 3 & 0 & 0 & 0 \\ \text { G2 } & 57 & 46 & 31 & 15 & 6 & 5 & 2 & 0 & 0 \\ \text { G3 } & 26 & 25 & 13 & 8 & 4 & 4 & 1 & 0 & 0\end{array}$

No. at risk

$\begin{array}{llllclllll}\text { G0-1a } & 64 & 49 & 27 & 13 & 6 & 4 & 2 & 1 & 0 \\ \text { G1b } & 28 & 25 & 13 & 11 & 4 & 4 & 0 & 0 & 0 \\ \text { G2 } & 57 & 46 & 31 & 15 & 6 & 5 & 2 & 0 & 0 \\ \text { G3 } & 26 & 25 & 14 & 8 & 5 & 4 & 2 & 0 & 0\end{array}$

Fig. 3 Kaplan-Meier curves for DFS and DSS in patients with ESCC treated with neoadjuvant therapy and surgery stratified by tumour regression grade according to Japanese system 


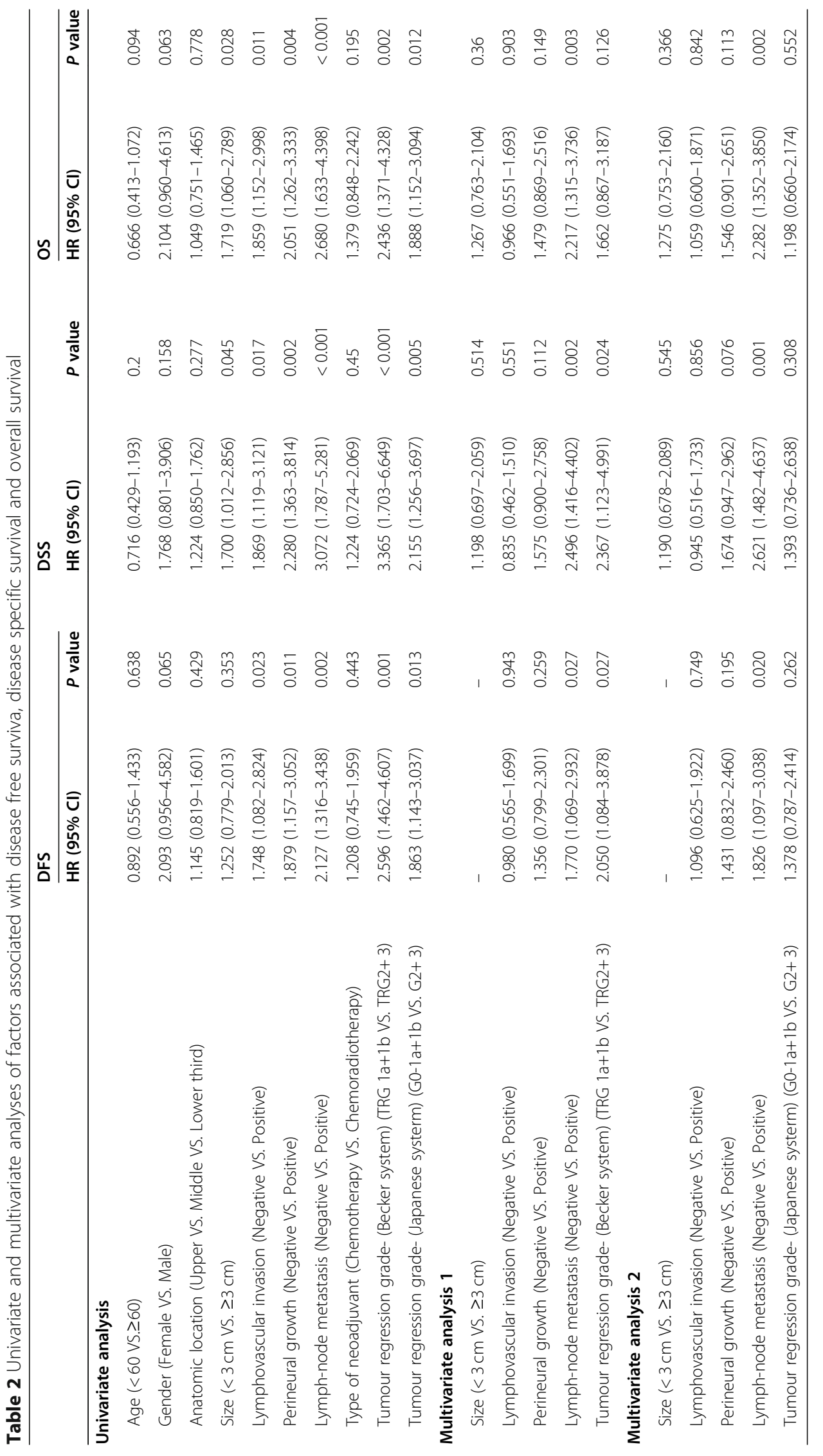




\section{TRG systems of Becker}

Among these systems, Becker et al. categorized TRG into four grades (TRG1a, 0\%, TRG1b, 1-10\%, TRG2, $11-50 \%$ and TRG3, > 50\%), which reflected prognosis and survival in a more object manner and widely accepted in tumour regression evaluation [19]. A step-bystep increase in tumour regression should be paralleled by a step-by-step increase in survival, however, some authors have argued whether the prognosis of cases showing $1-10 \%$ VRTC is inferior than those of patients with $0 \%$ VRTC $[15,31-33]$.

We reported a 5 -year DFS rates of $70.0 \%$, a DSS rate of $89.3 \%$ and an OS rate of $72.2 \%$ in TRG1a, a 5 -year DFS rates of $53.8 \%$, a DSS rate of $56.7 \%$ and an OS rate of $50.0 \%$ in TRG1b, a 5 -year DFS rates of $43.0 \%$, a DSS rate of $49.0 \%$ and an OS rate of $50.0 \%$ in TRG2, and a 5year DFS rates of $42.4 \%$, a DSS rate of $39.1 \%$ and an OS rate of $34.1 \%$ in TRG3. TRG1a or TRG1b have been associated with a statistically significant survival benefit compared with other regression classes. However, no statistically significant difference could be detected between TRG1a (0\% VRTC) and TRG1b (1-10\% VRTC) in our patients. Consistent with our results, recently published data indicated that no statistically significant difference could be detected between pathologic complete remission and microscopic residual disease in patients with EC, and TRG 1a-1b showed a statistically significant survival benefit compared with other regression classes [31, 34, 35]. This has also been reported for patients with non-small cell lung cancer [36], rectal cancer [37], as well as locally advanced gastric cancer [19] treated with neoadjuvant therapy. In our study, multivariate analysis confirmed that TRG according to Becker system was a potentially independent prognostic factor.

\section{TRG system of the Japanese classification of esophageal cancer}

The TRG system of the Japanese Classification of Esophageal Cancer was widely used in Japanese ESCC specimens [23, 30, 38]. Given the same histological subtype in China, Japanese grading system was also evaluated in our study: G0-1a, more than $2 / 3$ residual carcinoma, G1b, $1 / 3$ to $2 / 3$ residual carcinoma, G2, $<1 /$ 3 residual carcinoma and G3, 0\% residual carcinoma [20, 21]. Our date demonstrated that OS was best for patients with G3 and worst for patients with G0-1a, but there was no statistical difference in survival between patients with G1b and G2, who were in an intermediate prognostic category. The system was not significantly associated with DFS and OS in our multivariate analysis.

\section{Comparison between Becker and Japanese system}

The main difference between Becker system and Japanese system was the classification of patients with minimal residual tumour (1-10\% VRTC). Becker system divided these patients into TRG $1 \mathrm{~b}$, as an independent group, who had the similar 5-year survival rates as the whole cohort. Japanese system incorporated these patients into G2 (<1/3 VRTC) [19-21]. Studies using clinical response classifications according to Japanese grading system might underestimate the number of patients (1-10\% VRTC) with an impressive survival benefit. However, these studies distinguished the group with partial response $(<1 / 3$ VRTC) and the group with less response ( $>2 / 3$ VRTC), which recognized more patients with a survival benefit [23]. With the comparison of the two systems, we believed that the percentage of VRTC could also be used in regular pathology report, which would make the further study understandable and comparable.

\section{Conclusion}

In this study, we concluded that TRG according to both Becker system and Japanese system had its advantage in risk stratification of ESCC patients undergoing neoadjuvant therapy plus surgery. Based on Becker system, TRG was potentially independent predictors of patient outcome, which was not found based on Japanese system. The classification of cases showing 1-10\% VRTC made the grouping different. We would like to recommend not only TRG according to Becker's, Japanese and other systems but also the percentage of VRTC should be reported in the pathology evaluation, which could make study results more comparable among different research groups, and more understandable for oncologists in the clinical practice. Our findings might represent a valuable addition to the current literature in light of the increasing histopathologic response evaluation of neoadjuvant therapy in ESCC.

\section{Abbreviations}

VRTC: Visual Residual Tumour Cells; TRG: Tumour regression grading; ESCC: Esophageal squamous cell carcinoma; LNM: Lymph node metastases; EC: Esophageal cancer; nCT: Neoadjuvant chemotherapy; nCRT: Neoadjuvant chemoradiotherapy; DFS: Disease free survivalDSSDisease specific survival; OS: Overall survival; CT: Computed tomography; PET: Positron emission tomography; LN: Lymph nodes; HRs: Hazard rates

\section{Acknowledgements}

Not applicable.

\section{Authors' contributions}

$X W, H W 1, H W 2, J H, X W, Z J$, performed the research; LT, DJ, and YH designed the research study; XW, HW1 analysed the data; $L T, D J$, and YH wrote the paper. No conflict of interest exits in the submission of this manuscript, and manuscript is approved by all authors for publication.

\section{Funding}

This work was supported by Shanghai Natural Science Foundation of China (No. 18ZR1406800) for collection, National Natural Science Foundation of China (No. 81702372) for analysis, and Shanghai Municipal Commission of Science and Technology (No. 19441904000), Shanghai Municipal Key Clinical Specialty (No. shslczdzk01302), Shanghai Science and Technology Development 
Fund (No. 19MC1911000), and Xiamen Science and Technology Project of Fujian Province, China (No. 3502Z20184003) for writing.

\section{Availability of data and materials}

The datasets used and/or analysed during the current study are available from the cor-responding author on reasonable request.

\section{Ethics approval and consent to participate}

This study was approved by the Institutional Review Board of Zhongshan hospital, Fudan University (B2016-135) and was performed according to the ethical principles of the Declaration of Helsinki. The consent obtained from study participants was written.

\section{Consent for publication}

Not applicable.

\section{Competing interests}

The authors declare there is no conflict of interest.

\section{Author details}

'Department of Pathology, Zhongshan Hospital, Fudan University, Shanghai 200032, People's Republic of China. ${ }^{2}$ Department of Thoracic surgery, Zhongshan Hospital, Fudan University, Shanghai 200032, People's Republic of China. ${ }^{3}$ Department of Pathology, School of Basic Medical Sciences \& Zhongshan Hospital, Fudan University, Shanghai 200032, People's Republic of China. ${ }^{4}$ Department of Pathology, Qingpu Branch of Zhongshan Hospital, Fudan University, Shanghai 201700, People's Republic of China.

Received: 17 February 2019 Accepted: 29 December 2020 Published online: 03 February 2021

\section{References}

1. Fitzmaurice C, Dicker D, Pain A, Hamavid H, Moradi-Lakeh M, Maclntyre MF, et al. The global burden of cancer 2013. JAMA Oncol. 2015;1(4):505-27.

2. Chen W, Zheng R, Baade PD, Zhang S, Zeng H, Bray F, et al. Cancer statistics in China, 2015. CA Cancer J Clin. 2016;66(2):115-32.

3. Rustgi AK, El-Serag HB. Esophageal carcinoma. N Engl J Med. 2014;371(26): 2499-509.

4. Lagergren J, Smyth E, Cunningham D, Lagergren P. Oesophageal cancer. Lancet (London, England). 2017;390(10110):2383-96.

5. Pennathur A, Gibson MK, Jobe BA, Luketich JD. Oesophageal carcinoma. Lancet (London, England). 2013;381(9864):400-12.

6. Shapiro J, van Lanschot JJB, Hulshof M, van Hagen P, van Berge Henegouwen MI, Wijnhoven BPL, et al. Neoadjuvant chemoradiotherapy plus surgery versus surgery alone for oesophageal or junctional cancer (CROSS): long-term results of a randomised controlled trial. Lancet Oncol. 2015;16(9):1090-8

7. Mariette $C$, Robb WB, Piessen G, Adenis A. Neoadjuvant chemoradiation in oesophageal cancer. Lancet Oncol. 2015;16(9):1008-9.

8. Ohnuma H, Sato Y, Hayasaka N, Matsuno T, Fujita C, Sato M, et al. Neoadjuvant chemotherapy with docetaxel, nedaplatin, and fluorouracil for resectable esophageal cancer: a phase II study. Cancer Sci. 2018;109(11):3554-63.

9. Sato M, Ando N. Neoadjuvant chemotherapy followed by surgery as standard treatment for stage II + III thoracic esophageal squamous cell carcinoma in Japan. Nihon Geka Gakkai zasshi. 2011;112(2):104-10.

10. Al-Batran SE, Hofheinz RD, Pauligk C, Kopp HG, Haag GM, Luley KB, et al. Histopathological regression after neoadjuvant docetaxel, oxaliplatin, fluorouracil, and leucovorin versus epirubicin, cisplatin, and fluorouracil or capecitabine in patients with resectable gastric or gastro-oesophageal junction adenocarcinoma (FLOT4-AIO): results from the phase 2 part of a multicentre, open-label, randomised phase 2/3 trial. Lancet Oncol. 2016; 17(12):1697-708

11. Mandard AM, Dalibard F, Mandard JC, Marnay J, Henry-Amar M, Petiot JF, et al. Pathologic assessment of tumor regression after preoperative chemoradiotherapy of esophageal carcinoma. Clinicopathologic correlations. Cancer. 1994;73(11):2680-6.

12. Karamitopoulou E, Thies S, Zlobec I, Ott K, Feith M, Slotta-Huspenina J, et al. Assessment of tumor regression of esophageal adenocarcinomas after neoadjuvant chemotherapy: comparison of 2 commonly used scoring approaches. Am J Surg Pathol. 2014;38(11):1551-6.
13. Schmidt T, Sicic L, Blank S, Becker K, Weichert W, Bruckner T, et al. Prognostic value of histopathological regression in 850 neoadjuvantly treated oesophagogastric adenocarcinomas. Br J Cancer. 2014;110(7):171220.

14. Langer R, Ott K, Feith M, Lordick F, Siewert JR, Becker K. Prognostic significance of histopathological tumor regression after neoadjuvant chemotherapy in esophageal adenocarcinomas. Modern Pathol. 2009;22(12): 1555-63.

15. Brucher BL, Becker K, Lordick F, Fink U, Sarbia M, Stein H, et al. The clinical impact of histopathologic response assessment by residual tumor cell quantification in esophageal squamous cell carcinomas. Cancer. 2006; 106(10):2119-27.

16. Wu TT, Chirieac LR, Abraham SC, Krasinskas AM, Wang H, Rashid A, et al Excellent interobserver agreement on grading the extent of residual carcinoma after preoperative chemoradiation in esophageal and esophagogastric junction carcinoma: a reliable predictor for patient outcome. Am J Surg Pathol. 2007;31(1):58-64.

17. van Meerten E, Muller K, Tilanus HW, Siersema PD, Eijkenboom WM, van Dekken $\mathrm{H}$, et al. Neoadjuvant concurrent chemoradiation with weekly paclitaxel and carboplatin for patients with oesophageal cancer: a phase II study. Br J Cancer. 2006;94(10):1389-94.

18. Schneider PM, Baldus SE, Metzger R, Kocher M, Bongartz R, Bollschweiler E, et al. Histomorphologic tumor regression and lymph node metastases determine prognosis following neoadjuvant radiochemotherapy for esophageal cancer: implications for response classification. Ann Surg. 2005; 242(5):684-92

19. Becker K, Mueller JD, Schulmacher C, Ott K, Fink U, Busch R, et al. Histomorphology and grading of regression in gastric carcinoma treated with neoadjuvant chemotherapy. Cancer. 2003;98(7):1521-30.

20. Japan Esophageal Society. Japanese classification of esophageal cancer, 11th edition: part I. Esophagus. 2017;14(1):1-36.

21. Japan Esophageal Society. Japanese classification of esophageal cancer, 11th edition: part II and III. Esophagus. 2017;14(1):37-65.

22. Tong DK, Law S, Kwong DL, Chan KW, Lam AK, Wong KH. Histological regression of squamous esophageal carcinoma assessed by percentage of residual viable cells after neoadjuvant chemoradiation is an important prognostic factor. Ann Surg Oncol. 2010;17(8):2184-92.

23. Hatogai K, Fujii S, Kojima T, Daiko H, Kadota T, Fujita T, et al. Prognostic significance of tumor regression grade for patients with esophageal squamous cell carcinoma after neoadjuvant chemotherapy followed by surgery. J Surg Oncol. 2016;113(4):390-6.

24. Huang J, Song $Q$, Wang $H$, Wang $H$, Xu C, Wang $X$, et al. Poor prognostic impact of FGF4 amplification in patients with esophageal squamous cell carcinoma. Hum Pathol. 2018;80:210-8.

25. van Hagen P, Hulshof MC, van Lanschot JJ, Steyerberg EW, van Berge Henegouwen MI, Wijnhoven BP, et al. Preoperative chemoradiotherapy for esophageal or junctional cancer. N Engl J Med. 2012;366(22):2074-84.

26. Muijs C, Smit J, Karrenbeld A, Beukema J, Mul V, van Dam G, et al. Residual tumor after neoadjuvant chemoradiation outside the radiation therapy target volume: a new prognostic factor for survival in esophageal cancer. Int J Radiat Oncol Biol Phys. 2014;88(4):845-52.

27. Holscher AH, Bollschweiler E, Bogoevski D, Schmidt H, Semrau R, Izbicki JR. Prognostic impact of neoadjuvant chemoradiation in CT3 oesophageal cancer - a propensity score matched analysis. Eur J Cancer (Oxford. England 1990). 2014:50(17):2950-7.

28. Stahl M, Walz MK, Stuschke M, Lehmann N, Meyer HJ, Riera-Knorrenschild J, et al. Phase III comparison of preoperative chemotherapy compared with chemoradiotherapy in patients with locally advanced adenocarcinoma of the esophagogastric junction. J Clin Oncol. 2009;27(6):851-6.

29. Hermann RM, Horstmann O, Haller F, Perske C, Christiansen H, Hille A, et al. Histomorphological tumor regression grading of esophageal carcinoma after neoadjuvant radiochemotherapy: which score to use? Dis Esophagus. 2006;19(5):329-34.

30. Okumura H, Uchikado Y, Matsumoto M, Owaki T, Kita Y, Omoto I, et al. Prognostic factors in esophageal squamous cell carcinoma patients treated with neoadjuvant chemoradiation therapy. Int J Clin Oncol. 2013;18(2):329-34.

31. Holscher AH, Drebber U, Schmidt H, Bollschweiler E. Prognostic classification of histopathologic response to neoadjuvant therapy in esophageal adenocarcinoma. Ann Surg. 2014;260(5):779-84 discussion 784-775.

32. Chirieac LR, Swisher SG, Ajani JA, Komaki RR, Correa AM, Morris JS, et al. Posttherapy pathologic stage predicts survival in patients with esophageal 
carcinoma receiving preoperative chemoradiation. Cancer. 2005;103(7): 1347-55.

33. Chao YK, Chuang WY, Chang HK, Tseng CK, Yeh CJ, Liu YH. Prognosis of patients with esophageal squamous cell carcinoma who achieve major histopathological response after neoadjuvant chemoradiotherapy. Eur J Surg Oncol. 2017:43(1):234-9.

34. Francis AM, Sepesi B, Correa AM, Blum MA, Erasmus JJ, Lee JH, et al. The influence of histopathologic tumor viability on long-term survival and recurrence rates following neoadjuvant therapy for esophageal adenocarcinoma. Ann Surg. 2013;258(3):500-7.

35. Noble F, Nolan L, Bateman AC, Byrne JP, Kelly JJ, Bailey IS, et al. Refining pathological evaluation of neoadjuvant therapy for adenocarcinoma of the esophagus. World J Gastroenterol. 2013;19(48):9282-93.

36. Thomas M, Rube C, Semik M, von Eiff M, Freitag L, Macha HN, et al. Impact of preoperative bimodality induction including twice-daily radiation on tumor regression and survival in stage III non-small-cell lung cancer. J Clin Oncol. 1999;17(4):1185.

37. Ruo L, Tickoo S, Klimstra DS, Minsky BD, Saltz L, Mazumdar M, et al. Longterm prognostic significance of extent of rectal cancer response to preoperative radiation and chemotherapy. Ann Surg. 2002;236(1):75-81.

38. Akutsu Y, Shuto K, Kono T, Uesato M, Hoshino I, Shiratori T, et al. The number of pathologic lymph nodes involved is still a significant prognostic factor even after neoadjuvant chemoradiotherapy in esophageal squamous cell carcinoma. J Surg Oncol. 2012;105(8):756-60

\section{Publisher's Note}

Springer Nature remains neutral with regard to jurisdictional claims in published maps and institutional affiliations.

Ready to submit your research? Choose BMC and benefit from:

- fast, convenient online submission

- thorough peer review by experienced researchers in your field

- rapid publication on acceptance

- support for research data, including large and complex data types

- gold Open Access which fosters wider collaboration and increased citations

- maximum visibility for your research: over $100 \mathrm{M}$ website views per year

At $\mathrm{BMC}$, research is always in progress.

Learn more biomedcentral.com/submissions 